\title{
PAP SMEAR COVERAGE AND EFFECT OF KNOWLEDGE AND ATTITUDE REGARDING CERVICAL CANCER ON UTILIZATION OF THE TEST BY WOMEN IN UDAYAPUR DISTRICT OF NEPAL \\ S RANABHAT ${ }^{1}$ * , G DHUNGANA ${ }^{2}$, M NEUPANE ${ }^{3}$, R SHRESTHA $^{\mathbf{4}}$, M TIWARI $^{\mathbf{5}}$ \\ ${ }^{I}$ Department of Pathology, Chitwan Medical College, Bharatpur, Nepal \\ ${ }^{2}$ Department of Community Medicine, Faculty of Biostatistics, Bharatpur, Nepal \\ ${ }^{3}$ School of Nursing, Chitwan Medical College, Bharatpur, Nepal \\ ${ }^{4}$ Department of Pathology, Nepalese Army Institute of Health Sciences, Kathmandu, Nepal. \\ ${ }_{5}^{5}$ Department of Pathology, Chitwan Medical College, Bharatpur, Nepal \\ *Correspondence to: Dr. Sabin Ranabhat, Department of Pathology, Chitwan Medical College
}

E-mail:bhatsabin@gmail.com

\begin{abstract}
Background: Cervical cancer prevention, the most common cancer in women in Nepal, is almost nonexistent because of very low pap smear coverage. Material and methods: This study was done to find out pap smear coverage, to assess women's knowledge about cervical cancer and cervical pap smear, to assess women's attitude towards cervical pap smear, and to find out association of demographic variables, attitude of women towards pap smear test, and knowledge of cervical cancer and cervical pap smear test with its practice. It was a cross sectional analytical observational study which was carried out in a one-day free health camp organized in Udayapur district of Nepal jointly by Chitwan Medical College and Satya Sai Organization on January 5 of 2013. Participants were interviewed with the help of structured questionnaire. Fisher's exact test was done to detect association of the variables with pap smear practice. Results: Fisher's exact test showed that knowledge about pap smear test and attitude towards the test were the only variables which significantly influenced pap smear utilization $(\mathrm{p}=0.04)$. Pap smear utilization was not associated with age-at-marriage, age-at-menarche, parity and age-at-first-childbirth. Conclusion: Pap smear coverage was found to be $7.8 \%$ (at $95 \%$ CI was $0.02-0.13$ ) which is lower than the average for developing countries. This study has shown that knowledge about pap smear test and attitude towards the test significantly influence pap smear utilization. Therefore, work should be done towards that end to increase pap smear coverage.
\end{abstract}

Key Words: Attitude, Cervical Cancer, Knowledge, Nepal, Pap smear coverage

\section{INTRODUCTION}

Cervical cancer ranks fourth commonest cancer in women worldwide, while it is on the top spot in the developing countries. ${ }^{1}$ According to data of National Cancer Registry Programme (NCRP), cervical cancer is the number one malignancy among women in Nepal too. ${ }^{2}$

Fortunately, cervical cancer can be prevented by detecting it in its preinvasive stage with the help of smear test. Pap smear test also can decrease mortality by diagnosing cervical cancer at an early stage. ${ }^{3}$

Organized and spontaneous cervical pap smear screening programs are in place in developed countries for many decades. For example in Finland, population-based mass-screening programme was started from 1963 onwards. A centralized organization sends invitation letter to every eligible woman for the screening. More than 1,50,000 cervical smears are obtained per year by organized pap screening program. ${ }^{4}$

Effectiveness of pap smear test has been demonstrated by the decline of incidence of cervical cancer and its mortality rate in developed nations after initiation of mass screening programs in the last fifty years. The age-adjusted incidence of cervical carcinoma in Finland has decreased by about $80 \%$ since the advent of pap smear screening program. Canada was the first country to start organized pap smear screening program in 1949. Cervical cancer mortality has fallen from 13.5 per 1,00,000 in 1952 to 2.2 per $1,00,000$ in 2006 in Canada. ${ }^{5}$ Cervical cancer was number one in incidence in the USA fifty years ago; now it is in number 14 in that country because of pap smear. ${ }^{6}$ Closer home, Japan and South Korea have witnessed similar success story. ${ }^{7}$ Despite proven efficacy of the test, Nepal Government has not approved pap smear yet for the prevention of cervical cancer. The policy named as 'National guideline for cervical cancer screening and prevention in Nepal 2010' has 'Visual Inspection of cervix with Acetic Acid' as the screening tool instead of pap smear test. ${ }^{2}$

Although government initiative is lacking, a few women in Nepal are receiving opportunistic pap smear test on their own 
request or after advice from health workers in hospitals where there are gynecologists. Studies have found that utilization of such opportunistic screening test is affected, along with demographic variables, by knowledge of client about cervical cancer and pap smear test, and attitude towards the test. ${ }^{8,9}$

There is very scarce published information about pap smear test utilization by Nepalese women and its association with abovementioned variables.

\section{MATERIALS METHODS}

Objectives: The objectives of this study were to assess women's knowledge about cervical cancer and cervical pap smear, to assess women's attitude towards cervical pap smear, to find out pap smear coverage and to find out association of demographic factors, attitude of women towards cervical pap smear, and knowledge of cervical cancer and cervical pap smear test, and with its practice.

Study design and location: It was a cross sectional analytical observational study which was carried out in a one-day free health camp organized in Udayapur district of Nepal jointly by Chitwan Medical College and Satya Sai Organization on January 6 of 2013 .

Sampling method: All the married female clients who attended the aforementioned health camp were included into the study. An informed verbal consent was obtained from the clients before their inclusion in the study. Ethical approval for the study was received from the Institutional Review Board of Chitwan Medical College.

\section{DATA COLLECTION AND ANALYSIS:}

All the participants were interviewed by the first author and information was collected on a pre-tested structured questionnaire. The questionnaire included five questions in order to test knowledge, attitude and practice regarding cervical cancer and cervical pap smear utilization (Table No. 1). Demographic information was also included in the questionnaire.

Data from the questionnaires were entered into the IBM SPSS statistics 20 .

Women were divided into two groups in the following way:

a). Women having adequate knowledge versus women not having adequate knowledge on cervical cancer: Women who knew that cervix can be affected by cancer were said to have adequate knowledge about cervical cancer.

b). Women having adequate knowledge versus women not having adequate knowledge on cervical pap smear test: Women who knew that pap smear is the test that is used to detect neoplastic lesions of cervix were said to have adequate knowledge about cervical pap smear test.

c). Women having good attitude versus women having bad attitude towards cervical pap smear test: Women who agreed that pap smear can detect neoplastic lesion of cervix were said to have good attitude towards the test.

d). Women who had undergone at least one pap smear test previously were included in the calculation of pap smear coverage.
Statistical analysis was done between the two groups of participants as mentioned above.

Univariate analysis of the participants was done using frequency distribution and means. Cross tabulation analysis was carried out with Fishers exact test to find out the strength of association between the categorical variables. All statistical tests were performed using two-sided tests at 0.05 level of significance $(95 \%$ confidence interval).

\section{RESULTS}

Socio-demographic characteristics of participants:

In total, ninety women were included into the study. Sociodemographic information of the participants is outlined in Table 1.

Table 1. Sociodemographic variables of participants

\begin{tabular}{|c|c|}
\hline Characteristics & $\mathrm{n}=90(\%)$ \\
\hline \multicolumn{2}{|c|}{ Age category (years) } \\
\hline $19-30$ & $34(37.8)$ \\
\hline $31-42$ & $46(51.1)$ \\
\hline $43-54$ & $8(8.9)$ \\
\hline$>55$ & $2(2.2)$ \\
\hline Mean age $\pm(\mathrm{SD})$ & $34.0 \pm(9.0)$ \\
\hline \multicolumn{2}{|c|}{ Age at marriage (years) } \\
\hline$<18$ & $497(81.9)$ \\
\hline$>18$ & $110(18.1)$ \\
\hline Mean (SD) & $18.0 \pm(2.9)$ \\
\hline \multicolumn{2}{|l|}{ Parity } \\
\hline None & $1(1.1)$ \\
\hline 1 & $13(14.4)$ \\
\hline 2 & $26(28.9)$ \\
\hline$\geq 3$ & $47(52.2)$ \\
\hline Mean (median) & $2.8(3.0)$ \\
\hline \multicolumn{2}{|c|}{ Age at first child birth (years) } \\
\hline$<20$ & $61(70.9)$ \\
\hline $20-35$ & $25(29.1)$ \\
\hline$>35$ & $0(0.0)$ \\
\hline \multicolumn{2}{|l|}{ Urban residency } \\
\hline Yes & $70(77.8)$ \\
\hline No & $20(22.2)$ \\
\hline
\end{tabular}

Mean age of clients was $34(\mathrm{SD} \pm 9)$ years. Most of the women $(81.9 \%)$ were married before they reached the right age of marriage that is 18 years and $70.9 \%$ of women gave birth to a child before reaching the age of 20 . A little more than half $(52.2 \%)$ of all the clients had 3 or more children. Those women who had 2 children were only $28.9 \%$. 
Ranabhat et al, Journal of Chitwan Medical College 2014; 4(10)

Data on knowledge regarding cervical cancer and cervical pap smear test, attitude towards pap smear test and practice of the test are given in Table 2.

Table 2: KAP of the Nepali Female Population Surveyed Regarding Cervical Cancer and Pap smear test

\begin{tabular}{|l|l|}
\hline Variable & $n=90(\%)$ \\
\hline Knowledge about cancer of cervix: & $57(63.3)$ \\
\hline Adequate & $33(36.7)$ \\
\hline Inadequate & \multicolumn{2}{|l|}{} \\
\hline \multicolumn{2}{|l|}{ Knowledge about objective of cervical pap smear test: } \\
\hline Adequate & $24(26.7)$ \\
\hline Inadequate & $66(73.3)$ \\
\hline & \\
\hline Attitude: & $40(44.4)$ \\
\hline Favourable & $50(55.6)$ \\
\hline Unfavourable & \\
\hline \multicolumn{2}{|l|}{} \\
\hline Practice & $0(0.0)$ \\
\hline Adequate & $7(7.8)$ \\
\hline Pap smear at least once & $83(92.2)$ \\
\hline Never had undergone pap test & $0(0.00)$ \\
\hline $\begin{array}{l}\text { Knowledge about age of initiation and cessation, and } \\
\text { screening interval of pap smear test: }\end{array}$ & $90(100.0)$ \\
\hline Adequate & Inadequate \\
\hline
\end{tabular}

Although $63.3 \%$ of clients were aware of cervical cancer, $73.3 \%$ of women did not know why pap smear is done. There was not much difference between women who had good attitude towards cervical pap smear test $(44.4 \%)$ and women who had bad attitude towards the test (55.6\%).

Practice of pap smear or pap smear coverage: Only $7.8 \%$ (at 95\% CI was $0.02-0.13$ ) women had had at least one pap smear test previous to the current visit. Out of all the women who were screened at least once previously, $57.1 \%$ were in the early child-bearing agegroup of 18 to 34 years. The percentage of women who were in the late childbearing age-group of 35 to 45 years was $28.6 \%$.

Pap smear coverage is shown in pie diagram and proportion of pap smear coverage is shown in bar diagram.

Figure 1: Pie Diagram showing pap smear coverage $(n=90)$

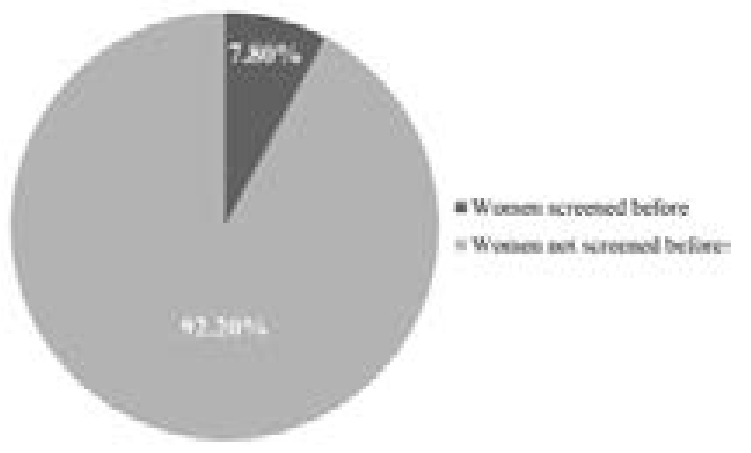

(C) 2014, JCMC. All Rights Reserved
Figure 2: Bar diagram showing proportion of age-group-wise pap smear coverage $(n=90)$

\section{$57.10 \%$}

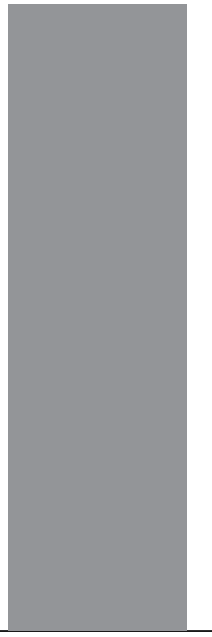

18-34 years

$28.60 \%$

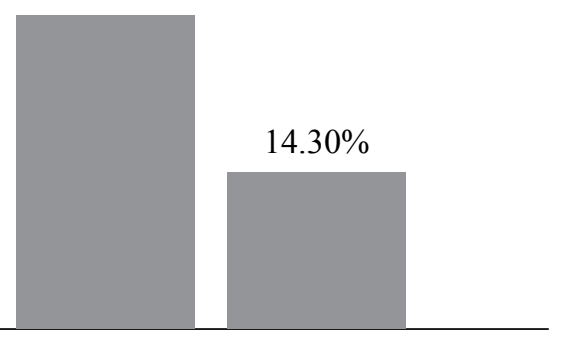

$35-45$ years

$>45$ years

Fisher's exact test: Analysis showed that knowledge about pap smear test and attitude towards the test were the only variables which significantly influenced pap smear utilization $(p=0.04)$. Findings in detail are shown in table 3.

Table 3. Analysis between dependent variable 'pap smear utilization' and covariates.

\begin{tabular}{|c|c|c|c|}
\hline \multirow[t]{2}{*}{ Variables } & \multicolumn{2}{|c|}{$\begin{array}{c}\text { Pap smear test } \\
\text { utilization }\end{array}$} & \multirow[t]{2}{*}{ p value } \\
\hline & Yes $(\%)$ & No $(\%)$ & \\
\hline \multicolumn{2}{|c|}{ Knowledge about Ca cervix } & & 1.0 \\
\hline Aware & $5(8.8)$ & $52(91.2)$ & \\
\hline Unaware & $2(6.1)$ & $31(93.9)$ & \\
\hline \multicolumn{2}{|c|}{ Knowledge about pap smear } & & 0.01 \\
\hline Aware & $5(20.8)$ & $19(79.2)$ & \\
\hline Unaware & $2(3.0)$ & $64(97.0)$ & \\
\hline Attitude & & & 0.04 \\
\hline Favourable & $6(15.0)$ & $34(85.0)$ & \\
\hline Unfavourable & $1(2.0)$ & $49(98.0)$ & \\
\hline Urban residency & & & 1.0 \\
\hline Yes & $6(8.6)$ & $64(91.4)$ & \\
\hline No & $1(5.0)$ & $19(95.0)$ & \\
\hline Age at marriage & & & 1.0 \\
\hline$<18$ & & $4(7.4)$ & \\
\hline$>18$ & & $3(8.6)$ & \\
\hline Age at first childbirth & & & 0.7 \\
\hline$<18$ & $2(5.9)$ & $32(94.1)$ & \\
\hline$>18$ & $5(9.6)$ & $47(90.4)$ & \\
\hline Age at menarche & & & 1.0 \\
\hline$<16$ & $5(7.5)$ & $62(92.5)$ & \\
\hline$>16$ & $2(9.1)$ & $20(90.9)$ & \\
\hline
\end{tabular}

Pap smear utilization was not significantly associated with other variables namely knowledge of cervical cancer, attitude 
towards pap smear test, urban residency, age at marriage, age at menarche and age at first child-birth.

\section{DISCUSSION}

True picture of pap smear coverage in Nepal is not known because not much research has been done on the topic. Government of Nepal has no data on the subject partly because pap smear is not the recommended test for cervical cancer prevention in the "National cervical cancer prevention policy of Nepal". ${ }^{2}$ Among few researches, Shrestha and Shah found it to be $10.5 \%$ in a study carried out in Kathmandu. ${ }^{9}$ Ranabhat et al. found it to be $15.7 \%$ in a research done in Chitwan district. ${ }^{10}$ According to ICO, cervical cancer screening rate, rather than pap smear coverage, is $2.4 \%$ in Nepal. ${ }^{11}$ There is a difference between pap smear coverage and cervical cancer screening rate. At least one pap smear test in the past is enough to calculate pap smear coverage. On the contrary, a woman should have followed guidelines developed by authoritative organizations (eg. American Cancer Society) to include her while calculating the screening rate. ${ }^{12,13,14,15}$

All the participants of this study were unaware of the recommended guidelines on the use of pap smear test. If the guidelines are to be followed to the dot, cervical cancer screening rate is zero in this study. However, pap smear coverage has been found to be $7.8 \%$ which is slightly lower than the one $(10.5 \%)$ found in a research done in Kathmandu, Nepal. ${ }^{9}$ People in Kathmandu are exposed more to information on health care issues which explains the higher value obtained in the study carried out there. But according to a study done in Bharatpur, coverage was found to be $29 \%$ for women in the age-group of 16 to 29 and $46.6 \%$ for women in the age-group of 30 to 44 years. ${ }^{16}$ These figures are far higher than found by any studies done in Nepal so far. We are not able to explain such a huge disparity of data.

Average figures of pap smear coverage in developing countries, developed countries and across the globe are as follows: $18.5 \%, 63 \%$ and $39.6 \%$ respectively. ${ }^{17}$ The figure of pap smear coverage obtained by this study $(7.8 \%)$ is below that of developing countries and also below the global average.

According to WHO, if a woman can be screened only once in her lifetime because of low resources, the best age is between 35 and 45 years. $^{3}$ In our study, out of all the women who had undergone at least one pap smear test, only $28.6 \%$ were from that age-group. Majority $(57.1 \%)$ were in the age-group of 18 to 34 years. This finding is nearly similar to findings of a Mexican study in which the highest proportion of clients were found in the age-group of 25 to 35 years. ${ }^{18}$ But in a study done in Chitwan district of Nepal by Ranabhat et al., $64 \%$ of all the clients were in the age-group of 30 to 49 years. ${ }^{19}$

Pap smear uptake by women can be affected by many variables, some of which are mentioned below: age, age at marriage, age at menarche, age at first child birth, parity, urban residency, knowledge about cervical cancer and pap smear test, and attitude towards cervical pap smear test.
Fisher's exact test was used to find out the variables which significantly affected pap smear uptake. Out of the abovementioned variables, knowledge about pap smear test and attitude towards the test were found to affect pap smear test utilization significantly ( $\mathrm{p}=0.01$ and 0.04 respectively). In a study done in Kathmandu, Nepal, 65.7\% of women had heard about cervical cancer but only $10.5 \%$ had utilized pap smear for the prevention of cervical cancer. Lack of knowledge about pap smear test played a significant role in poor uptake of pap smear by women in that study. Only $18 \%$ were aware of pap smear test in that study which is near our finding of $26.7 \% .^{9}$ In a study in Ethiopia, pap smear coverage was found to be $6.5 \% .81 .2 \%$ of participants had never heard of pap smear. ${ }^{20}$ Similar observation was made in an Iranian study in which pap smear coverage was found to be $27 \%$. History of pap smear utilization and good knowledge about pap smear were significantly associated with each other. ${ }^{21}$

Women across all age-groups and regardless of parity, urban residency, age at marriage and age at first child birth should be targeted as significant relationship of pap smear test utilization with these variables was not found in this study.

\section{LIMITATION OF THE STUDY:}

Future researches should also address extrinsic barriers of pap smear test utilization. For example 'Not receiving advice to do the test from health care workers' is the most common reason for not doing the test in some studies. ${ }^{22,23}$

\section{CONCLUSION:}

Pap smear coverage in this study has been found to be $7.8 \%$ (at $95 \%$ CI was $0.02-0.13$ ) which is much lower than the average for developing countries. Among several variables, knowledge about pap smear test and attitude towards the test were found to be significantly associated with pap smear test utilization. Thus, health education programs should focus on increasing knowledge of women on pap smear test. At the same time, the programs should be effective in bringing about positive change in attitude of women towards the test.

Acknowledgement: We are grateful to Chitwan Medical College management and Satya Sai Organization, Nepal for making it possible to carry out the research in the one-day health camp organized in Udayapur district of Nepal. Thanks are also due to personnel of different academic capacities in the department of pathology and gynecology who have contributed in many ways.

\section{REFERENCES:}

1. Ferlay J, Soerjomataram I, Ervik M, Dikshit R, Eser S, Mathers C et al. GLOBOCAN 2012 v1.0, Cancer Incidence and Mortality Worldwide: IARC Cancer Base No. 11. Lyon, France: International Agency for Research on Cancer; 2013.

2. Family Health Division (FHD). National Guideline for Cervical Cancer Screening and Prevention in Nepal; 2011.

3. World Health Organization: WHO. Comprehensive cervical cancer control: a guide to essential practice; 2006.

4. Nieminen P, Kallio M, Anttila, Hakama M. Organized vs. 
spontaneous pap-smear screening for cervical cancer: a case-control study. Int J Cancer 1999;83: 55-58.

5. Dickinson JA, Stankiewicz A, Popadiuk C, Pogany L, Onysko J, Miller AB. Reduced cervical cancer incidence and mortality in Canada: national data from 1932 to 2006. BMC Public Health 2012;12:992.

6. Siegel R, Naishadham D, Jemal A. Cancer statistics. CA Cancer J Clin 2012;62:10-29.

7. Konno R, Shin HR, Kim YT, Song YS, Sasagawa T, Inoue M, Park JS. Human Papillomavirus Infection and Cervical Cancer Prevention in Japan and Korea. Vaccine 2008;26(12): 30-42.

8. Aswathy S, Quereshi MA, Kurian B, Leelamoni K. Cervical cancer screening: current knowledge \& practice among women in a rural population of Kerala, India. Indian J Med Res 2012;136:205-210.

9. Shrestha J, Saha R, Tripathi N. Knowledge, attitude and practice regarding cervical cancer screening amongst women visiting tertiary centre in Kathmandu, Nepal. Nepal Journal of Medical sciences 2013;2(2):85-90.

10. Ranabhat S, Tiwari M, Dhungana G, Shrestha R. Association of knowledge, attitude and demographic variables with cervical pap smear practice in Nepal. Asian Pac J Cancer Prev 2014;15(20):8905-8910.

11. "Institute Cagtala d'Oncologia" [ICO] Information Centre on HPV and Cancer. Human Papillomavirus and Related Cancers in Nepal, Fact Sheet. 2013.

12. ACS recommendation statement. 2014.

13. U.S. Preventive Services Task Force: USPSTF. Screening for Cervical Cancer. 2012.

14. National Cervical Screening Program (2005). Screening to prevent cervical cancer: Guidelines for the management of asymptomatic women with screen detected abnormalities. 2005.

15. Canadian Task Force on Preventive Health Care. Recommendations on screening for cervical cancer. CMAJ. 2013;185 (1).

16. Sherpa ATL. Time for an organized cervical cancer screening in Bharatpur, Nepal. [dissertation]. University of Oslo, Norway; 2007.
17. Gakidou E, Nordhagen S, Obermeyer Z. Coverage of cervical cancer screening in 57 countries: low average levels and large inequalities.

18. Leyva M, Byrd T, Tarwater P. Attitudes towards cervical cancer screening: a study of beliefs among women in Mexico. CJHP 2006;4(2):13-24.

19. Ranabhat SK, Shrestha R, Tiwari M. Analysis of abnormal epithelial lesions in cervical Pap smears in Mid-Western Nepal. JPN 2011;1:30-33.

20. Terefe Y, Gaym A. Knowledge, attitude and practice of screening for carcinoma of the cervix among reproductive health clients at three teaching hospitals, Addis Ababa, Ethiopia. Ethiopian Journal of Reproductive Health 2008;2(1).

21. Chamani S R, Charandabi S M, Kamalifard M. Knowledge, Attitudes and Practice about Pap Smear among Women referring to A Public Hospital. Journal of Family and Reproductive Health 2012;6(4).

22. Al-Naggar RA, Low WY, Isa ZM. Knowledge and barriers towards cervical cancer screening among young women in Malaysia. Asian Pacific J Cancer Prev 2010;11:867-73.

23. Thippeveeranna C, Mohan SS, Singh LR, Singh NN. Knowledge, attitude and practice of the pap Smear as a screening procedure among nurses in a tertiary hospital in North Eastern India. Asian Pac J Cancer Prev 2013;14(2):849-52. 